\title{
PERBANDINGAN SAHAM HANG SENG DAN NIKKEI MENGGUNAKAN ALGORITMA HEBBIAN
}

\author{
Fitri Yanti ${ }^{1}$ dan Jaka Sutrisna ${ }^{2}$ \\ ${ }^{1,2}$ Staf Pengajar Fakultas Teknik Prodi Teknik Informatika \\ Universitas Pamulang, Tangerang Selatan, Banten \\ ${ }^{1}$ fitriyantid@gmail.com \\ 2jakasutrisna@gmail.com
}

\begin{abstract}
ABSTRAK
Pasar modal salah satu penggerak perekonomian suatu negara dan sarana representasi untuk menilai kondisi perusahaan-perusahaan disuatu negara, karena hampir semua industri di suatu negara terwakili oleh pasar modal. Semakin besar saham yang dimiliki, maka semakin besar pula kekuasaannya di perusahaan tersebut. Hanseng merupakan Bursa Saham Hong Kong dan Nikkei merupakan Bursa Saham Tokyo. Jaringan saraf tiruan salah satunya algoritma hebbian, pada algoritma hebbian aturan pelatihan yang paling awal dan paling sederhana untuk jaringan syaraf tiruan secara umum. Pada aturan hebbian ini pelatihan yang terjadi yaitu dengan memodifikasi kekuatan sinapsis (bobot). Data ditunjukkan dalam angka bipolar yaitu (1 dan -1). Dengan menggunakan metode jaringan saraf tiruan-algoritma hebbian maka dapat membandingkan antara nikkei dan hanseng mana yang lebih baik.
\end{abstract}

Kata Kunci: Perbandingan, Saham, Algoritma Hebbian

\section{PENDAHULUAN}

Pasar modal merupakan salah satu penggerak perekonomian suatu negara dan sarana representasi untuk menilai kondisi perusahaanperusahaan disuatu negara, karena hampir semua industri di suatu negara terwakili oleh pasar modal. Pembelian saham menjadi salah satu pilihan modal yang sah, selain bentuk modal lainnya seperti uang, tanah, dan emas.Implikasi dari adanya pilihan saham sebagai salah satu pilihan investasi, baik itu jangka panjang maupun jangka pendek, mempunyai arti yang luas karena harga saham berbeda dengan uang. Ketika indeks satu indeks mengalami kenaikan maka indeks lainnya mengalami kenaikan, demikian juga sebaliknya. Hal ini mengindikasikan adanya hubungan antar bursa dan memberikan pengaruh kepada bursa yang lainnya. Penelitian yang dilakukan oleh Noer Azam Achsani (2000) tentang bagaimana bursa merespon terhadap syok dari bursa lain, apabila terjadi syok di Amerika Serikat maka bursa saham di Asia Pasifik tidak akan terlalu merespon, hanya di Singapura, Hong Kong, Jepang dan Taiwan dan New Zealand yang akanlangsung merespon, namun tidak cukup besar. Sebaliknya jika syok terjadi di bursa Singapura, Australia atau Hong Kong, secara cepat shock tersebut akan ditransmisikan ke hampir semua bursa saham di Asia Pasifik, termasuk BEJ. Ludovicus Sensi Wondabio (2000) menyatakan bahwa pola hubungan antara
JSX (Jakarta Stock Index), FTSE (Financial Times Stock Index), NIKKEI dan SSI (Singapore Stock Price Index) ternyata memiliki hubungan yang berbeda-beda. Bila kondisi ekonomi suatu negara baik maka indeks saham akan menunjukkan adanya trend yang meningkat tetapi jika kondisi ekonomi suatu negara dalam keadaan turun maka akan memengaruhi juga terhadap indeks saham tersebut. Penelitian terkait telah banyak dilakukan baik dengan kelebiahna dan kerurangan masing-masing. Di penelitian ini saya hanya perbandingan nikkei dan Hanseng dengan menggunakan algoritma hebbian.

\section{TINJAUAN PUSTAKA}

\subsection{Saham}

Saham merupakan surat berharga yang bersifat kepemilikan. Semakin besar saham yang dimiliki, maka semakin besar pula kekuasaannya di perusahaan tersebut.

\subsection{Hanseng}

Hanseng Adalah kapitalisasi pasar tertimbang freefloat-disesuaikan indeks pasar saham di Hong Kong. Indeks ini digunakan untuk memonitor dan mencatat perubahan harian dari perusahaan-perusahaan terbesar di pasar saham Hong Kong dan merupakan indikator utama dari keseluruhan performa pasar di Hong Kong.

\subsection{Nikkei}


Nikkei 225 adalah sebuah indeks pasar saham untuk Bursa Saham Tokyo (Tokyo Stock Exchange - TSE). Ia telah dihitung setiap hari oleh surat kabar Nihon Keizai Shimbun (Nikkei) sejak tahun 1950. Indeks ini adalah harga rata-rata tertimbang (dalam satuan yen), dan komponennya ditinjau ulang setahun sekali.

\section{4 jaringan syaraf tiruan}

Jaringan syaraf tiruan (JST) adalah paradigma pemrosesan suatu informasi yang terinspirasi oleh sistem sel syaraf biologi. Untuk menentukan output, setiap neuron menggunakan fungsi aktivasi (biasanya bukan fungsi linier) yang dikenakan pada jumlahan input yang diterima. Besarnya output ini selanjutnya dibandingkan dengan suatu batas ambang.

\section{5 algoritma hebbian}

Hebb rule adalah aturan pelatihan yang paling awal dan paling sederhana untuk jaringan syaraf tiruan secara umum. Pada aturan hebbian ini pelatihan yang terjadi yaitu dengan memodifikasi kekuatan sinapsis (bobot).

Jika data ditunjukkan dalam bentuk bipolar, ini mudah untuk menyatakan pembaharuan bobot yang diinginkan sehingga persamaan bobot:

$$
\begin{aligned}
& \mathrm{W}_{\mathrm{i}}(\text { baru })=\mathrm{W}_{\mathrm{i}}(\text { lama })+\mathrm{x}_{\mathrm{i}} \mathrm{y} \\
& \text { Perbaikan bias } \\
& \mathrm{b}(\text { baru })=\mathrm{b}(\text { lama })+\mathrm{y}
\end{aligned}
$$

\section{METODE PENELITIAN}

Langkah-langkah yang akan dilakukan dalam perbandingan hanseng dan nikkei dengan menggunakan algoritma hebbian:

a. Data Histori hanseng dan nikkei.

b. Data di normalisasikan dalam bentuk angka bipolar (angka 1 dan -1).

c. Proses Algoritma hebbian.

d. Traning data .

e. Uji model/testing.

f. Membandingkan hanseng dan nikkei

g. Hasil data terbaik

Metode yang diusulkan

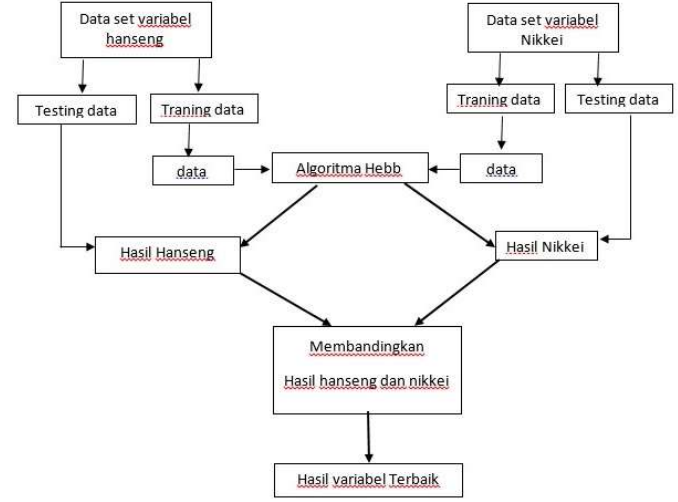

3.1 Gambar metode yang di usulkan

Tabel 3.1 Data Histori saham hanseng di bulan februari

\begin{tabular}{|l|l|l|l|l|r|}
\hline \multicolumn{7}{|c|}{ data input } \\
\hline tanggal & open & high & Low & close & volume \\
\hline $02 / 01 / 2017$ & 18970 & 19285 & 18900 & 19185 & 110666 \\
\hline $02 / 02 / 2017$ & 19620 & 19680 & 19550 & 19565 & 114802 \\
\hline $02 / 03 / 2017$ & 19070 & 19095 & 18800 & 19060 & 122527 \\
\hline $02 / 06 / 2017$ & 19090 & 19095 & 18795 & 18840 & 87901 \\
\hline $02 / 07 / 2017$ & 18855 & 18970 & 18790 & 18920 & 74566 \\
\hline $02 / 08 / 2017$ & 18955 & 19040 & 18860 & 18955 & 73372 \\
\hline $02 / 09 / 2017$ & 18945 & 19210 & 18860 & 19170 & 90735 \\
\hline $02 / 10 / 2017$ & 19165 & 19450 & 19165 & 19355 & 134280 \\
\hline $02 / 13 / 2017$ & 19425 & 19530 & 19355 & 19485 & 96980 \\
\hline $02 / 14 / 2017$ & 19485 & 19510 & 19250 & 19475 & 22455 \\
\hline $02 / 15 / 2017$ & 19480 & 19500 & 19335 & 19415 & 80933 \\
\hline $02 / 16 / 2017$ & 19440 & 19460 & 19170 & 19225 & 93122 \\
\hline $02 / 17 / 2017$ & 19260 & 19265 & 19020 & 19150 & 93306 \\
\hline $02 / 20 / 2017$ & 19180 & 19275 & 19100 & 19270 & 72328 \\
\hline $02 / 21 / 2017$ & 19290 & 19470 & 19240 & 19455 & 58227 \\
\hline $02 / 22 / 2017$ & 19440 & 19460 & 19270 & 19325 & 77067 \\
\hline $02 / 23 / 2017$ & 19365 & 19375 & 19220 & 19290 & 76907 \\
\hline $02 / 24 / 2017$ & 19265 & 19385 & 19080 & 19130 & 93428 \\
\hline $02 / 27 / 2017$ & 19185 & 19220 & 18990 & 19210 & 108992 \\
\hline $02 / 28 / 2017$ & 19215 & 19270 & 19020 & 19100 & 81782 \\
\hline
\end{tabular}

Sumber equite word

Tabel 3.2 Data di normalisasi dalam bentuk angka bipolar (angka 1 dan -1)

\begin{tabular}{|c|c|c|c|c|c|}
\hline \multirow{2}{*}{ tanggal } & \multicolumn{5}{|c|}{ normalisasi } \\
\cline { 2 - 6 } & $\mathbf{x 1}$ & $\mathbf{x 2}$ & $\mathbf{x 3}$ & $\mathbf{x 4}$ & $\mathbf{x 5}$ \\
\hline $02 / 01 / 2017$ & -1 & -1 & -1 & -1 & -1 \\
\hline $02 / 02 / 2017$ & -1 & -1 & -1 & -1 & -1 \\
\hline $02 / 03 / 2017$ & -1 & -1 & -1 & -1 & -1 \\
\hline $02 / 06 / 2017$ & -1 & -1 & -1 & -1 & -1 \\
\hline $02 / 07 / 2017$ & -1 & -1 & -1 & -1 & -1 \\
\hline
\end{tabular}




\begin{tabular}{|l|r|r|r|r|r|}
$02 / 08 / 2017$ & -1 & -1 & -1 & -1 & -1 \\
\hline $02 / 09 / 2017$ & -1 & -1 & -1 & -1 & -1 \\
\hline $02 / 10 / 2017$ & -1 & -1 & -1 & -1 & -1 \\
\hline $02 / 13 / 2017$ & -1 & -1 & -1 & -1 & -1 \\
\hline $02 / 14 / 2017$ & 1 & -1 & 1 & -1 & -1 \\
\hline $02 / 15 / 2017$ & 1 & 1 & 1 & 1 & -1 \\
\hline $02 / 16 / 2017$ & 1 & 1 & 1 & 1 & -1 \\
\hline $02 / 17 / 2017$ & 1 & 1 & 1 & 1 & -1 \\
\hline $02 / 20 / 2017$ & 1 & 1 & 1 & 1 & -1 \\
\hline $02 / 21 / 2017$ & 1 & 1 & 1 & 1 & -1 \\
\hline $02 / 22 / 2017$ & 1 & 1 & 1 & 1 & -1 \\
\hline $02 / 23 / 2017$ & 1 & 1 & 1 & 1 & -1 \\
\hline $02 / 24 / 2017$ & 1 & 1 & 1 & 1 & -1 \\
\hline $02 / 27 / 2017$ & 1 & 1 & 1 & 1 & -1 \\
\hline $02 / 28 / 2017$ & 1 & 1 & 1 & 1 & -1 \\
\hline
\end{tabular}

Tabel 3.3 Target dan bias

\begin{tabular}{|r|r|}
\hline target & Bias \\
\hline-1 & 1 \\
\hline-1 & 1 \\
\hline-1 & 1 \\
\hline-1 & 1 \\
\hline-1 & 1 \\
\hline-1 & 1 \\
\hline-1 & 1 \\
\hline-1 & 1 \\
\hline-1 & 1 \\
\hline-1 & 1 \\
\hline-1 & 1 \\
\hline-1 & 1 \\
\hline-1 & 1 \\
\hline-1 & 1 \\
\hline-1 & 1 \\
\hline-1 & 1 \\
\hline-1 & 1 \\
\hline-1 & 1 \\
\hline-1 & 1 \\
\hline-1 & 1 \\
\hline-1 & 1 \\
\hline-1 & 1 \\
\hline-1 & 1 \\
\hline
\end{tabular}

Tabel 3.4 Perhitungan algoritma hebbian

\begin{tabular}{|l|l|l|}
\hline Data 1: & Data 2: & Data 3: \\
$w_{1}=0+-1 \times-1=1$ & $w_{1}=1+-1 \times-1=2$ & $w_{1}=2+-1 \times-1=3$ \\
$w_{2}=0+-1 \times-1=1$ & $w_{2}=1+-1 \times-1=2$ & $w_{2}=2+-1 \times-1=3$ \\
$w_{3}=0+-1 \times-1=1$ & $w_{3}=1+-1 \times-1=2$ & $w_{3}=2+-1 \times-1=3$ \\
$w_{4}=0+-1 \times-1=1$ & $w_{4}=1+-1 \times-1=2$ & $w_{4}=2+-1 \times-1=3$ \\
$w_{5}=0+-1 \times-1=1$ & $w_{5}=1+-1 \times-1=2$ & $w_{5}=2+-1 \times-1=3$ \\
$b=0+-1=-1$ & $b=-1+-1=-2$ & $b=-2+-1=-3$ \\
\hline
\end{tabular}

\begin{tabular}{|c|c|c|}
\hline $\begin{array}{l}\text { Data 4: } \\
w_{1}=3+-1 \times-1=4 \\
w_{2}=3+-1 \times-1=4 \\
w_{3}=3+-1 \times-1=4 \\
w_{4}=3+-1 \times-1=4 \\
w_{5}=3+-1 \times-1=4 \\
b=-3+-1=-4\end{array}$ & $\begin{array}{l}\text { Data 5: } \\
w_{1}=4+-1 \times-1=5 \\
w_{2}=4+-1 \times-1=5 \\
w_{3}=4+-1 \times-1=5 \\
w_{4}=4+-1 \times-1=5 \\
w_{5}=4+-1 \times-1=5 \\
b=-4+-1=-5\end{array}$ & $\begin{array}{l}\text { Data 6: } \\
w_{1}=5+-1 \times-1=6 \\
w_{2}=5+-1 \times-1=6 \\
w_{3}=5+-1 \times-1=6 \\
w_{4}=5+-1 \times-1=6 \\
w_{5}=5+-1 \times 1=4 \\
b=-5+-1=-6\end{array}$ \\
\hline $\begin{array}{l}\text { Data 7: } \\
w_{1}=6+-1 \times-1=7 \\
w_{2}=6+-1 \times-1=7 \\
w_{3}=6+-1 \times-1=7 \\
w_{4}=6+-1 \times-1=7 \\
w_{5}=4+-1 \times-1=5 \\
b=-6+-1=-7\end{array}$ & $\begin{array}{l}\text { Data 8: } \\
w_{1}=7+-1 \times-1=8 \\
w_{2}=7+-1 \times-1=8 \\
w_{3}=7+-1 \times-1=8 \\
w_{4}=7+-1 \times-1=8 \\
w_{5}=5+-1 \times-1=6 \\
b=-7+-1=-8\end{array}$ & $\begin{array}{l}\text { Data 9: } \\
w_{1}=8+-1 \times-1=9 \\
w_{2}=8+-1 \times-1=9 \\
w_{3}=8+-1 \times-1=9 \\
w_{4}=8+-1 \times-1=9 \\
w_{5}=6+-1 \times-1=7 \\
b=-8+-1=-9\end{array}$ \\
\hline $\begin{array}{l}\text { Data 10: } \\
w_{1}=9+1 \times-1=8 \\
w_{2}=9+-1 \times-1=10 \\
w_{3}=9+1 \times-1=8 \\
w_{4}=9+-1 \times-1=10 \\
w_{5}=7+-1 \times-1=8 \\
b=-9+-1=-10\end{array}$ & $\begin{array}{l}\text { Data 11: } \\
w_{1}=8+1 \times-1=7 \\
w_{2}=10+1 \times-1=9 \\
w_{3}=8+1 \times-1=7 \\
w_{4}=10+1 \times-1=9 \\
w_{5}=8+1 \times-1=7 \\
b=-10+-1=-11\end{array}$ & $\begin{array}{l}\text { Data 12: } \\
w_{1}=7+1 \times-1=6 \\
w_{2}=9+1 \times-1=8 \\
w_{3}=7+1 \times-1=6 \\
w_{4}=9+1 \times-1=8 \\
w_{5}=7+-1 \times-1=8 \\
b=-11+-1=-12\end{array}$ \\
\hline $\begin{array}{l}\text { Data 13: } \\
w_{1}=6+1 \times-1=5 \\
w_{2}=8+1 \times-1=7 \\
w_{3}=6+1 \times-1=5 \\
w_{4}=8+1 \times-1=7 \\
w_{5}=8+-1 \times-1=9 \\
b=-12+-1=-13\end{array}$ & $\begin{array}{l}\text { Data 14: } \\
w_{1}=5+1 \times-1=4 \\
w_{2}=7+1 \times-1=6 \\
w_{3}=5+1 \times-1=4 \\
w_{4}=7+1 \times-1=6 \\
w_{5}=9+-1 \times-1=10 \\
b=-13+-1=-14\end{array}$ & $\begin{array}{l}\text { Data 15: } \\
w_{1}=4+1 \times-1=3 \\
w_{2}=6+1 \times-1=5 \\
w_{3}=4+1 \times-1=3 \\
w_{4}=6+1 \times-1=5 \\
w_{5}=10+1 \times-1=9 \\
b=-14+-1=-15\end{array}$ \\
\hline $\begin{array}{l}\text { Data 16: } \\
w_{1}=3+1 \times-1=2 \\
w_{2}=5+1 \times-1=4 \\
w_{3}=3+1 \times-1=2 \\
w_{4}=5+1 \times-1=4 \\
w_{5}=9+1 \times-1=8 \\
b=-15+-1=-16\end{array}$ & $\begin{array}{l}\text { Data 17: } \\
w_{1}=2+1 \times-1=1 \\
w_{2}=4+1 \times-1=3 \\
w_{3}=2+1 \times-1=1 \\
w_{4}=4+1 \times-1=3 \\
w_{5}=8+1 \times-1=7 \\
b=-16+-1=-17\end{array}$ & $\begin{array}{l}\text { Data 18: } \\
w_{1}=1+1 \times-1=0 \\
w_{2}=3+1 \times-1=2 \\
w_{3}=1+1 \times-1=0 \\
w_{4}=3+1 \times-1=2 \\
w_{5}=7+1 \times-1=6 \\
b=-17+-1=-18\end{array}$ \\
\hline $\begin{array}{l}\text { Data 19: } \\
w_{1}=0+1 \times-1=-1 \\
w_{2}=2+1 \times-1=1 \\
w_{3}=0+1 \times-1=-1 \\
w_{4}=2+1 \times-1=1 \\
w_{5}=6+1 \times-1=5 \\
b=-18+-1=-19\end{array}$ & $\begin{array}{l}\text { Data 20: } \\
w_{1}=-1+1 \times-1=-2 \\
w_{2}=1+1 \times-1=0 \\
w_{3}=-1+1 \times-1=-2 \\
w_{4}=1+1 \times-1=0 \\
w_{5}=5+1 \times-1=4 \\
b=-19+-1=-20\end{array}$ & \\
\hline
\end{tabular}

Tabel 3.5 Perubahan bobot-bias dan Bobot barubias

\begin{tabular}{|c|c|c|c|c|c|c|c|c|c|c|c|}
\hline \multicolumn{6}{|c|}{ perbaikan bobot-bias } & \multicolumn{6}{|c|}{ bobot baru-bias } \\
\hline$\Delta \mathbf{x 1}$ & $\Delta \mathbf{x} 2$ & $\Delta \mathbf{x} 3$ & $\Delta x 4$ & $\Delta x 5$ & $\Delta \mathbf{b}$ & w1 & w2 & w3 & w4 & w5 & b \\
\hline 1 & 1 & 1 & 1 & 1 & -1 & 1 & 1 & 1 & 1 & 1 & -1 \\
\hline 1 & 1 & 1 & 1 & 1 & -1 & 2 & 2 & 2 & 2 & 2 & -2 \\
\hline 1 & 1 & 1 & 1 & 1 & -1 & 3 & 3 & 3 & 3 & 3 & -3 \\
\hline 1 & 1 & 1 & 1 & 1 & -1 & 4 & 4 & 4 & 4 & 4 & -4 \\
\hline 1 & 1 & 1 & 1 & 1 & -1 & 5 & 5 & 5 & 5 & 5 & -5 \\
\hline 1 & 1 & 1 & 1 & 1 & -1 & 6 & 6 & 6 & 6 & 6 & -6 \\
\hline 1 & 1 & 1 & 1 & 1 & -1 & 7 & 7 & 7 & 7 & 7 & -7 \\
\hline 1 & 1 & 1 & 1 & 1 & -1 & 8 & 8 & 8 & 8 & 8 & -8 \\
\hline 1 & 1 & 1 & 1 & 1 & -1 & 9 & 9 & 9 & 9 & 9 & -9 \\
\hline-1 & 1 & -1 & 1 & 1 & -1 & 8 & 10 & 8 & 10 & 10 & -10 \\
\hline-1 & -1 & -1 & -1 & 1 & -1 & 7 & 9 & 7 & 9 & 11 & -11 \\
\hline-1 & -1 & -1 & -1 & 1 & -1 & 6 & 8 & 6 & 8 & 12 & -12 \\
\hline-1 & -1 & -1 & -1 & 1 & -1 & 5 & 7 & 5 & 7 & 13 & -13 \\
\hline-1 & -1 & -1 & -1 & 1 & -1 & 4 & 6 & 4 & 6 & 14 & -14 \\
\hline-1 & -1 & -1 & -1 & 1 & -1 & 3 & 5 & 3 & 5 & 15 & -15 \\
\hline-1 & -1 & -1 & -1 & 1 & -1 & 2 & 4 & 2 & 4 & 16 & -16 \\
\hline-1 & -1 & -1 & -1 & 1 & -1 & 1 & 3 & 1 & 3 & 17 & -17 \\
\hline-1 & -1 & -1 & -1 & 1 & -1 & $\mathbf{0}$ & 2 & 0 & 2 & 18 & -18 \\
\hline-1 & -1 & -1 & -1 & 1 & -1 & -1 & 1 & -1 & 1 & 19 & -19 \\
\hline-1 & -1 & -1 & -1 & 1 & -1 & -2 & 0 & -2 & 0 & 20 & -20 \\
\hline
\end{tabular}

Bobot baru $=(-2,0,-2,0,20,-20)$

Outputnya

$y_{1}=-2 x-1+0 x-1+-2 x-1+0 x-1+4 x-1+(-20)=-36$ 
ISSN 2541-1004

$y_{2}=-2 \mathrm{x}-1+0 \mathrm{x}-1+-2 \mathrm{x}-1+0 \mathrm{x}-1+4 \mathrm{x}-1+(-20)=-36$

$y_{3}=-2 \mathrm{x}-1+0 \mathrm{x}-1+-2 \mathrm{x}-1+0 \mathrm{x}-1+4 \mathrm{x}-1+(-20)=-36$

$y_{4}=-2 \mathrm{x}-1+0 \mathrm{x}-1+-2 \mathrm{x}-1+0 \mathrm{x}-1+4 \mathrm{x}-1+(-20)=-36$

$y_{5}=-2 \mathrm{x}-1+0 \mathrm{x}-1+-2 \mathrm{x}-1+0 \mathrm{x}-1+4 \mathrm{x}-1+(-20)=-36$

$y_{6}=-2 \mathrm{x}-1+0 \mathrm{x}-1+-2 \mathrm{x}-1+0 \mathrm{x}-1+4 \mathrm{x}-1+(-20)=-36$

$y_{7}=-2 \mathrm{x}-1+0 \mathrm{x}-1+-2 \mathrm{x}-1+0 \mathrm{x}-1+4 \mathrm{x}-1+(-20)=-36$

$y_{8}=-2 \mathrm{x}-1+0 \mathrm{x}-1+-2 \mathrm{x}-1+0 \mathrm{x}-1+4 \mathrm{x}-1+(-20)=-36$

$y_{9}=-2 \mathrm{x}-1+0 \mathrm{x}-1+-2 \mathrm{x}-1+0 \mathrm{x}-1+4 \mathrm{x}-1+(-20)=-36$

$y_{10}=-2 \mathrm{x} 1+0 \mathrm{x}-1+-2 \mathrm{x} 1+0 \mathrm{x}-1+4 \mathrm{x}-1+(-20)=-44$

$y_{11}=-2 \mathrm{x} 1+0 \mathrm{x} 1+-2 \mathrm{x} 1+0 \mathrm{x} 1+4 \mathrm{x}-1+(-20)=-44$

$y_{12}=-2 \mathrm{x}-1+0 \mathrm{x}-1+-2 \mathrm{x}-1+0 \mathrm{x}-1+4 \mathrm{x}-1+(-20)=-44$

$y_{13}=-2 \mathrm{x}-1+0 \mathrm{x}-1+-2 \mathrm{x}-1+0 \mathrm{x}-1+4 \mathrm{x}-1+(-20)=-44$

$y_{14}=-2 \mathrm{x}-1+0 \mathrm{x}-1+-2 \mathrm{x}-1+0 \mathrm{x}-1+4 \mathrm{x}-1+(-20)=-44$

$y_{15}=-2 \mathrm{x}-1+0 \mathrm{x}-1+-2 \mathrm{x}-1+0 \mathrm{x}-1+4 \mathrm{x}-1+(-20)=-44$

$y_{16}=-2 \mathrm{x}-1+0 \mathrm{x}-1+-2 \mathrm{x}-1+0 \mathrm{x}-1+4 \mathrm{x}-1+(-20)=-44$

$y_{17}=-2 x-1+0 x-1+-2 x-1+0 x-1+4 x-1+(-20)=-44$

$y_{18}=-2 \mathrm{x}-1+0 \mathrm{x}-1+-2 \mathrm{x}-1+0 \mathrm{x}-1+4 \mathrm{x}-1+(-20)=-44$

$y_{19}=-2 \mathrm{x}-1+0 \mathrm{x}-1+-2 \mathrm{x}-1+0 \mathrm{x}-1+4 \mathrm{x}-1+(-20)=-44$

$y_{20}=-2 x-1+0 x-1+-2 x-1+0 x-1+4 x-1+(-20)=-44$

Apabila outputnya di atas nilai 1 maka hasilnya 1 sedangkan dibawah 0 dan -1 hasilnya -1 untuk bilangan bipolar

Tabel 3.6 Hasil Output

\begin{tabular}{|l|l|l|}
\hline \multicolumn{3}{|c|}{ OUTPUT } \\
\hline y1 & -36 & -1 \\
\hline y2 & -36 & -1 \\
\hline y3 & -36 & -1 \\
\hline y4 & -36 & -1 \\
\hline y5 & -36 & -1 \\
\hline y6 & -36 & -1 \\
\hline y7 & -36 & -1 \\
\hline y8 & -36 & -1 \\
\hline y9 & -36 & -1 \\
\hline y10 & -44 & -1 \\
\hline y11 & -44 & -1 \\
\hline y12 & -44 & -1 \\
\hline y13 & -44 & -1 \\
\hline y14 & -44 & -1 \\
\hline y15 & -44 & -1 \\
\hline y16 & -44 & -1 \\
\hline y17 & -44 & -1 \\
\hline y18 & -44 & -1 \\
\hline y19 & -44 & -1 \\
\hline y20 & -44 & -1 \\
\hline
\end{tabular}

Tabel 3.7 Data Histori saham nikkei di bulan februari

\begin{tabular}{|c|l|l|l|l|r|}
\hline \multicolumn{7}{|c|}{ data input } \\
\hline Tanggal & open & high & Low & close & volume \\
\hline $02 / 01 / 2017$ & 18970 & 19285 & 18900 & 19185 & 110666 \\
\hline $02 / 02 / 2017$ & 19620 & 19680 & 19550 & 19565 & 114802 \\
\hline $02 / 03 / 2017$ & 19070 & 19095 & 18800 & 19060 & 122527 \\
\hline $02 / 06 / 2017$ & 19090 & 19095 & 18795 & 18840 & 87901 \\
\hline $02 / 07 / 2017$ & 18855 & 18970 & 18790 & 18920 & 74566 \\
\hline $02 / 08 / 2017$ & 18955 & 19040 & 18860 & 18955 & 73372 \\
\hline
\end{tabular}

\begin{tabular}{|l|l|l|l|l|r|}
$02 / 09 / 2017$ & 18945 & 19210 & 18860 & 19170 & 90735 \\
\hline $02 / 10 / 2017$ & 19165 & 19450 & 19165 & 19355 & 134280 \\
\hline $02 / 13 / 2017$ & 19425 & 19530 & 19355 & 19485 & 96980 \\
\hline $02 / 14 / 2017$ & 19485 & 19510 & 19250 & 19475 & 22455 \\
\hline $02 / 15 / 2017$ & 19480 & 19500 & 19335 & 19415 & 80933 \\
\hline $02 / 16 / 2017$ & 19440 & 19460 & 19170 & 19225 & 93122 \\
\hline $02 / 17 / 2017$ & 19260 & 19265 & 19020 & 19150 & 93306 \\
\hline $02 / 20 / 2017$ & 19180 & 19275 & 19100 & 19270 & 72328 \\
\hline $02 / 21 / 2017$ & 19290 & 19470 & 19240 & 19455 & 58227 \\
\hline $02 / 22 / 2017$ & 19440 & 19460 & 19270 & 19325 & 77067 \\
\hline $02 / 23 / 2017$ & 19365 & 19375 & 19220 & 19290 & 76907 \\
\hline $02 / 24 / 2017$ & 19265 & 19385 & 19080 & 19130 & 93428 \\
\hline $02 / 27 / 2017$ & 19185 & 19220 & 18990 & 19210 & 108992 \\
\hline $02 / 28 / 2017$ & 19215 & 19270 & 19020 & 19100 & 81782 \\
\hline
\end{tabular}

Sumber equite word

Tabel 3.8 Data di normalisasi dalam bentuk angka bipolar (angka 1 dan -1)

\begin{tabular}{|l|r|r|r|r|r|}
\hline \multirow{2}{*}{ Tanggal } & \multicolumn{5}{|c|}{ Normalisasi } \\
\cline { 2 - 6 } & $\mathrm{x} 1$ & $\mathrm{x} 2$ & $\mathrm{x} 3$ & $\mathrm{x} 4$ & $\mathrm{x} 5$ \\
\hline $02 / 01 / 2017$ & -1 & -1 & -1 & -1 & 1 \\
\hline $02 / 02 / 2017$ & 1 & 1 & 1 & 1 & 1 \\
\hline $02 / 03 / 2017$ & -1 & -1 & -1 & -1 & 1 \\
\hline $02 / 06 / 2017$ & -1 & -1 & -1 & -1 & -1 \\
\hline $02 / 07 / 2017$ & -1 & -1 & -1 & -1 & -1 \\
\hline $02 / 08 / 2017$ & -1 & -1 & -1 & -1 & -1 \\
\hline $02 / 09 / 2017$ & -1 & -1 & -1 & -1 & 1 \\
\hline $02 / 10 / 2017$ & -1 & 1 & 1 & 1 & 1 \\
\hline $02 / 13 / 2017$ & 1 & 1 & 1 & 1 & 1 \\
\hline $02 / 14 / 2017$ & 1 & 1 & 1 & 1 & -1 \\
\hline $02 / 15 / 2017$ & 1 & 1 & 1 & 1 & -1 \\
\hline $02 / 16 / 2017$ & 1 & 1 & 1 & -1 & 1 \\
\hline $02 / 17 / 2017$ & 1 & -1 & -1 & -1 & 1 \\
\hline $02 / 20 / 2017$ & -1 & -1 & 1 & 1 & -1 \\
\hline $02 / 21 / 2017$ & 1 & 1 & 1 & 1 & -1 \\
\hline $02 / 22 / 2017$ & 1 & 1 & 1 & 1 & -1 \\
\hline $02 / 23 / 2017$ & 1 & 1 & 1 & 1 & -1 \\
\hline $02 / 24 / 2017$ & 1 & 1 & -1 & -1 & 1 \\
\hline $02 / 27 / 2017$ & -1 & -1 & -1 & -1 & 1 \\
\hline $02 / 28 / 2017$ & -1 & -1 & -1 & -1 & -1 \\
\hline
\end{tabular}

Tabel 3.9 Target dan bias

\begin{tabular}{|r|r|}
\hline target & Bias \\
\hline-1 & 1 \\
\hline-1 & 1 \\
\hline-1 & 1 \\
\hline-1 & 1 \\
\hline-1 & 1 \\
\hline-1 & 1 \\
\hline-1 & 1 \\
\hline-1 & 1 \\
\hline-1 & 1 \\
\hline
\end{tabular}




\begin{tabular}{|l|l|}
\hline-1 & 1 \\
\hline-1 & 1 \\
\hline-1 & 1 \\
\hline-1 & 1 \\
\hline-1 & 1 \\
\hline-1 & 1 \\
\hline-1 & 1 \\
\hline-1 & 1 \\
\hline-1 & 1 \\
\hline-1 & 1 \\
\hline-1 & 1 \\
\hline-1 & 1 \\
\hline-1 & 1 \\
\hline-1 & 1 \\
\hline
\end{tabular}

Tabel 3.10 Perhitungan algoritma hebbian

\begin{tabular}{|c|c|c|}
\hline $\begin{array}{l}\text { Data 1: } \\
w_{1}=0+-1 \times-1=1 \\
w_{2}=0+-1 \times-1=1 \\
w_{3}=0+-1 \times-1=1 \\
w_{4}=0+-1 \times-1=1 \\
w_{5}=0+1 \times-1=-1 \\
b=0+-1=-1\end{array}$ & $\begin{array}{l}\text { Data 2: } \\
w_{1}=1+1 \times-1=0 \\
w_{2}=1+1 \times-1=0 \\
w_{3}=1+1 \times-1=0 \\
w_{4}=1+1 \times-1=0 \\
w_{5}=-1+1 \times-1=-2 \\
b=-1+-1=-2\end{array}$ & $\begin{array}{l}\text { Data 3: } \\
w_{1}=0+-1 \times-1=1 \\
w_{2}=0+-1 \times-1=1 \\
w_{3}=0+-1 \times-1=1 \\
w_{4}=0+-1 \times-1=1 \\
w_{5}=-2+1 \times-1=-3 \\
b=-2+1=-3\end{array}$ \\
\hline $\begin{array}{l}\text { Data 4: } \\
w_{1}=1+-1 \times-1=2 \\
w_{2}=1+-1 \times-1=2 \\
w_{3}=1+-1 \times-1=2 \\
w_{4}=1+-1 \times-1=2 \\
w_{5}=-3+1 \times-1=-2 \\
b=-3+-1=-4\end{array}$ & $\begin{array}{l}\text { Data 5: } \\
w_{1}=2+-1 \times-1=3 \\
w_{2}=2+-1 \times-1=3 \\
w_{3}=2+-1 \times-1=3 \\
w_{4}=2+-1 \times-1=3 \\
w_{5}=-2+-1 \times-1=-1 \\
b=-4+-1=-5\end{array}$ & $\begin{array}{l}\text { Data 6: } \\
w_{1}=3+-1 \times-1=4 \\
w_{2}=3+-1 \times-1=4 \\
w_{3}=3+-1 \times-1=4 \\
w_{4}=3+-1 \times-1=4 \\
w_{5}=-1+-1 \times-1=0 \\
b=-5+-1=-6\end{array}$ \\
\hline $\begin{array}{l}\text { Data } 7: \\
w_{1}=4+-1 \times-1=5 \\
w_{2}=4+-1 \times-1=5 \\
w_{3}=4+-1 \times-1=5 \\
w_{4}=4+-1 \times-1=5 \\
w_{5}=0+1 \times-1=-1 \\
b=-6+-1=-7\end{array}$ & \begin{tabular}{|l} 
Data 8: \\
$w_{1}=5+-1 \times-1=6$ \\
$w_{2}=5+1 \times-1=4$ \\
$w_{3}=5+1 \times-1=4$ \\
$w_{4}=5+1 \times-1=4$ \\
$w_{5}=-1+1 \times-1=-2$ \\
$b=-7+-1=-8$ \\
\end{tabular} & $\begin{array}{l}\text { Data 9: } \\
w_{1}=6+1 \times-1=5 \\
w_{2}=4+1 \times-1=3 \\
w_{3}=4+1 \times-1=3 \\
w_{4}=4+1 \times-1=3 \\
w_{5}=-2+1 \times-1=-3 \\
b=-8+-1=-9\end{array}$ \\
\hline $\begin{array}{l}\text { Data 10: } \\
w_{1}=5+1 \times-1=4 \\
w_{2}=3+1 \times-1=2 \\
w_{3}=3+1 \times-1=2 \\
w_{4}=3+1 \times-1=2 \\
w_{5}=-3+-1 \times-1=-2 \\
b=-9+-1=-10\end{array}$ & \begin{tabular}{|l} 
Data 11: \\
$w_{1}=4+1 \times-1=3$ \\
$w_{2}=2+1 \times-1=1$ \\
$w_{3}=2+1 \times-1=1$ \\
$w_{4}=2+1 \times-1=1$ \\
$w_{5}=-2+-1 \times-1=-1$ \\
$b=-10+-1=-11$ \\
\end{tabular} & $\begin{array}{l}\text { Data 12: } \\
w_{1}=3+1 \times-1=2 \\
w_{2}=1+1 \times-1=0 \\
w_{3}=1+1 \times-1=0 \\
w_{4}=1+-1 \times-1=2 \\
w_{5}=-1+1 \times-1=-2 \\
b=-11+-1=-12\end{array}$ \\
\hline $\begin{array}{l}\text { Data 13: } \\
w_{1}=2+1 \times-1=1 \\
w_{2}=0+-1 \times-1=1 \\
w_{3}=0+-1 \times-1=1 \\
w_{4}=2+-1 \times-1=3 \\
w_{5}=-2+1 \times-1=-3 \\
b=-12+-1=-13\end{array}$ & $\begin{array}{l}\text { Data 14: } \\
w_{1}=1+-1 \times-1=2 \\
w_{2}=1+-1 \times-1=2 \\
w_{3}=1+1 \times-1=0 \\
w_{4}=3+1 \times-1=2 \\
w_{5}=-3+-1 \times-1=-2 \\
b=-13+-1=-14\end{array}$ & $\begin{array}{l}\text { Data 15: } \\
w_{1}=2+1 \times-1=1 \\
w_{2}=2+1 \times-1=1 \\
w_{3}=0+1 \times-1=-1 \\
w_{4}=2+1 \times-1=1 \\
w_{5}=-2+-1 \times-1=-1 \\
b=-14+-1=-15\end{array}$ \\
\hline $\begin{array}{l}\text { Data 16: } \\
w_{1}=1+1 \times-1=0 \\
w_{2}=1+1 \times-1=0 \\
w_{3}=-1+1 \times-1=-2 \\
w_{4}=1+1 \times-1=0 \\
w_{5}=-1+-1 \times-1=0 \\
b=-15+-1=-16\end{array}$ & $\begin{array}{l}\text { Data 17: } \\
w_{1}=0+1 \times-1=-1 \\
w_{2}=0+1 \times-1=-1 \\
w_{3}=-2+1 \times-1=-3 \\
w_{4}=0+1 \times-1=-1 \\
w_{5}=0+-1 \times-1=1 \\
b=-16+-1=-17\end{array}$ & $\begin{array}{l}\text { Data 18: } \\
w_{1}=-1+1 \times-1=-2 \\
w_{2}=-1+1 \times-1=-2 \\
w_{3}=-3+-1 \times-1=-2 \\
w_{4}=-1+-1 \times-1=0 \\
w_{5}=1+1 \times-1=0 \\
b=-17+-1=-18\end{array}$ \\
\hline $\begin{array}{l}\text { Data 19: } \\
w_{1}=-2+-1 \times-1=-1 \\
w_{2}=-2+-1 \times-1=-1 \\
w_{3}=-2+-1 \times-1=-1 \\
w_{4}=0+-1 \times-1=1 \\
w_{5}=0+1 \times-1=-1 \\
b=-18+-1=-19\end{array}$ & $\begin{array}{l}\text { Data 20: } \\
w_{1}=-1+-1 \times-1=0 \\
w_{2}=-1+-1 \times-1=0 \\
w_{3}=-1+-1 \times-1=0 \\
w_{4}=1+-1 \times-1=2 \\
w_{5}=-1+-1 \times-1=0 \\
b=-19+-1=-20\end{array}$ & \\
\hline
\end{tabular}

Tabel 3.11 Perubahan bobot-bias dan Bobot baru bias baru

\begin{tabular}{|c|c|c|c|c|c|c|c|c|c|c|c|}
\hline \multicolumn{6}{|c|}{ Perubahan bobot-bias } & \multicolumn{6}{|c|}{ Bobot baru-bias } \\
\hline$\Delta \mathbf{x} 1$ & $\Delta \mathbf{x} 2$ & $\Delta \times 3$ & $\Delta \times \mathbf{x}$ & $\Delta \times 5$ & $\Delta \mathbf{b}$ & w1 & w2 & w3 & w4 & w5 & b \\
\hline 1 & 1 & 1 & 1 & -1 & -1 & 1 & 1 & 1 & 1 & -1 & -1 \\
\hline-1 & -1 & -1 & -1 & -1 & -1 & $\mathbf{0}$ & $\mathbf{0}$ & $\mathbf{0}$ & $\mathbf{0}$ & -2 & -2 \\
\hline 1 & 1 & 1 & 1 & -1 & -1 & 1 & 1 & 1 & 1 & -3 & -3 \\
\hline 1 & 1 & 1 & 1 & 1 & -1 & 2 & 2 & 2 & 2 & -2 & -4 \\
\hline 1 & 1 & 1 & 1 & 1 & -1 & 3 & 3 & 3 & 3 & -1 & -5 \\
\hline 1 & 1 & 1 & 1 & 1 & -1 & 4 & 4 & 4 & 4 & $\mathbf{0}$ & -6 \\
\hline 1 & 1 & 1 & 1 & -1 & -1 & 5 & 5 & 5 & 5 & -1 & -7 \\
\hline 1 & -1 & -1 & -1 & -1 & -1 & 6 & 4 & 4 & 4 & -2 & -8 \\
\hline-1 & -1 & -1 & -1 & -1 & -1 & 5 & 3 & 3 & 3 & -3 & -9 \\
\hline-1 & -1 & -1 & -1 & 1 & -1 & 4 & 2 & 2 & 2 & -2 & -10 \\
\hline-1 & -1 & -1 & -1 & 1 & -1 & 3 & 1 & 1 & 1 & -1 & -11 \\
\hline-1 & -1 & -1 & 1 & -1 & -1 & 2 & $\mathbf{0}$ & $\mathbf{0}$ & 2 & -2 & -12 \\
\hline-1 & 1 & 1 & 1 & -1 & -1 & 1 & 1 & 1 & 3 & -3 & -13 \\
\hline 1 & 1 & -1 & -1 & 1 & -1 & 2 & 2 & 0 & 2 & -2 & -14 \\
\hline-1 & -1 & -1 & -1 & 1 & -1 & 1 & 1 & -1 & 1 & -1 & -15 \\
\hline-1 & -1 & -1 & -1 & 1 & -1 & 0 & 0 & -2 & $\mathbf{0}$ & $\mathbf{0}$ & -16 \\
\hline-1 & -1 & -1 & -1 & 1 & -1 & -1 & -1 & -3 & -1 & 1 & -17 \\
\hline-1 & -1 & 1 & 1 & -1 & -1 & -2 & -2 & -2 & $\mathbf{0}$ & $\mathbf{0}$ & -18 \\
\hline 1 & 1 & 1 & 1 & -1 & -1 & -1 & -1 & -1 & 1 & -1 & -19 \\
\hline 1 & 1 & 1 & 1 & 1 & -1 & 0 & 0 & 0 & 2 & 0 & -20 \\
\hline
\end{tabular}

Bobot Baru $=(0,0,0,2,0,-20)$

Outputnya

$y_{1}=0 \mathrm{x}-1+0 \mathrm{x}-1+0 \mathrm{x}-1+2 \mathrm{x}-1+0 \mathrm{x} 1+(-20)=-22$

$y_{2}=0 \times 1+0 \times 1+0 \times 1+2 \times 1+0 \times 1+(-20)=-18$

$y_{3}=0 \mathrm{x}-1+0 \mathrm{x}-1+0 \mathrm{x}-1+2 \mathrm{x}-1+0 \mathrm{x} 1+(-20)=-22$

$y_{4}=0 \mathrm{x}-1+0 \mathrm{x}-1+0 \mathrm{x}-1+2 \mathrm{x}-1+0 \mathrm{x}-1+(-20)=-22$

$y_{5}=0 \mathrm{x}-1+0 \mathrm{x}-1+0 \mathrm{x}-1+2 \mathrm{x}-1+0 \mathrm{x}-1+(-20)=-22$

$y_{6}=0 \mathrm{x}-1+0 \mathrm{x}-1+0 \mathrm{x}-1+2 \mathrm{x}-1+0 \mathrm{x}-1+(-20)=-22$

$y_{7}=0 \mathrm{x}-1+0 \mathrm{x}-1+0 \mathrm{x}-1+2 \mathrm{x}-1+0 \mathrm{x} 1+(-20)=-22$

$y_{8}=0 \mathrm{x}-1+0 \mathrm{x} 1+0 \mathrm{x} 1+2 \mathrm{x} 1+0 \mathrm{x} 1+(-20)=-18$

$y_{9}=0 \times 1+0 \times 1+0 \times 1+2 \times 1+0 \times 1+(-20)=-18$

$y_{10}=0 \mathrm{x} 1+0 \mathrm{x} 1+0 \mathrm{x} 1+2 \mathrm{x} 1+0 \mathrm{x}-1+(-20)=-18$

$y_{11}=0 \mathrm{x} 1+0 \mathrm{x} 1+0 \mathrm{x} 1+2 \mathrm{x} 1+0 \mathrm{x}-1+(-20)=-18$

$y_{12}=0 \mathrm{x} 1+0 \mathrm{x} 1+0 \mathrm{x} 1+2 \mathrm{x}-1+0 \mathrm{x} 1+(-20)=-22$

$y_{13}=0 \mathrm{x} 1+0 \mathrm{x}-1+0 \mathrm{x}-1+2 \mathrm{x}-1+0 \mathrm{x} 1+(-20)=-22$

$y_{14}=0 \mathrm{x}-1+0 \mathrm{x}-1+0 \mathrm{x} 1+2 \mathrm{x} 1+0 \mathrm{x}-1+(-20)=-18$

$y_{15}=0 \mathrm{x} 1+0 \mathrm{x} 1+0 \mathrm{x} 1+2 \mathrm{x} 1+0 \mathrm{x}-1+(-20)=-18$

$y_{16}=0 \mathrm{x} 1+0 \mathrm{x} 1+0 \mathrm{x} 1+2 \mathrm{x} 1+0 \mathrm{x}-1+(-20)=-18$

$y_{17}=0 \mathrm{x} 1+0 \mathrm{x} 1+0 \mathrm{x} 1+2 \mathrm{x} 1+0 \mathrm{x}-1+(-20)=-18$

$y_{18}=0 \mathrm{x} 1+0 \mathrm{x} 1+0 \mathrm{x}-1+2 \mathrm{x}-1+0 \mathrm{x} 1+(-20)=-22$

$y_{19}=0 \mathrm{x}-1+0 \mathrm{x}-1+0 \mathrm{x}-1+2 \mathrm{x}-1+0 \mathrm{x} 1+(-20)=-22$

$y_{20}=0 \mathrm{x}-1+0 \mathrm{x}-1+0 \mathrm{x}-1+2 \mathrm{x}-1+0 \mathrm{x}-1+(-20)=-22$

Apabila outputnya di atas nilai 1 maka hasilnya 1 sedangkan dibawah 0 dan -1 hasilnya -1 untuk bilangan bipolar

Tabel 3.12 Hasil Output

\begin{tabular}{|l|l|l|}
\hline \multicolumn{3}{|c|}{ OUTPUT } \\
\hline y1 & -22 & -1 \\
\hline y2 & -18 & -1 \\
\hline y3 & -22 & -1 \\
\hline y4 & -22 & -1 \\
\hline y5 & -22 & -1 \\
\hline y6 & -22 & -1 \\
\hline y7 & -22 & -1 \\
\hline y8 & -18 & -1 \\
\hline
\end{tabular}




\begin{tabular}{|l|l|l|} 
y9 & -18 & -1 \\
\hline y10 & -18 & -1 \\
\hline y11 & -18 & -1 \\
\hline y12 & -22 & -1 \\
\hline y13 & -22 & -1 \\
\hline y14 & -18 & -1 \\
\hline y15 & -18 & -1 \\
\hline y16 & -18 & -1 \\
\hline y17 & -18 & -1 \\
\hline y18 & -22 & -1 \\
\hline y19 & -22 & -1 \\
\hline y20 & -22 & -1 \\
\hline
\end{tabular}

\section{HASIL DAN PEMBAHASAN}

\section{Home}

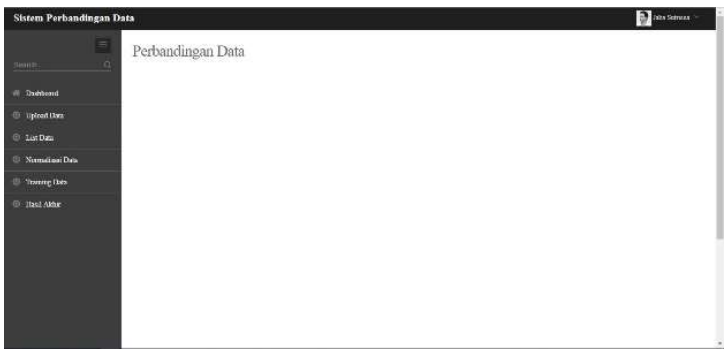

Gambar 4.1 Home

\section{Data hanseng dan nikkei}

Data histori hanseng dan nikkei

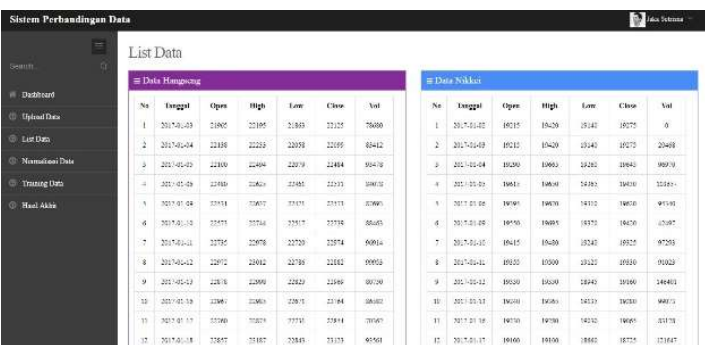

Gambar 4.2 Data history hanseng dan nikkei

\section{Normalisasi hanseng dan nikkei}

Setelah itu pilih normalisasi yang mengubah data histori hanseng dan nikkei di ubah dalam bentuk angka bipolar

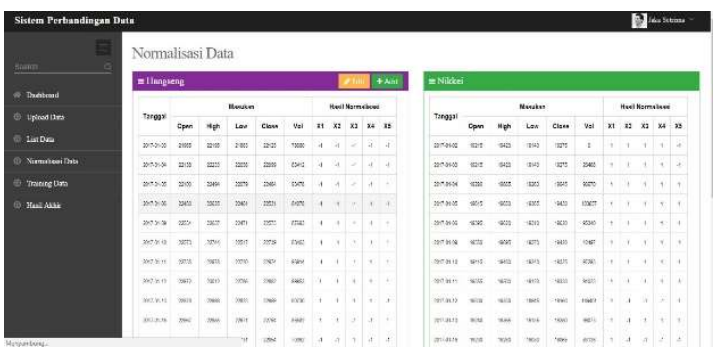

Gambar 4.3 Normalisasi hanseng dan nikkei

\section{Traning}

Klik Traning untuk melatih data normalisasi dengan perhitungan algoritma hebbian

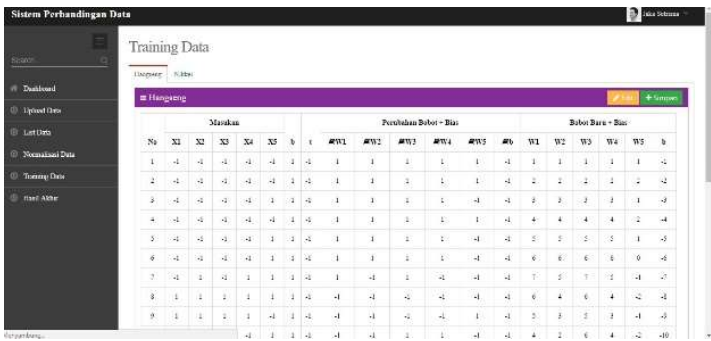

Gambar 4.4 Traning data hanseng dan nikkei

\section{Output}

Hasil keluaran dari uji coba data dengan menggunakan bobot akhir pada algoritma hebbian

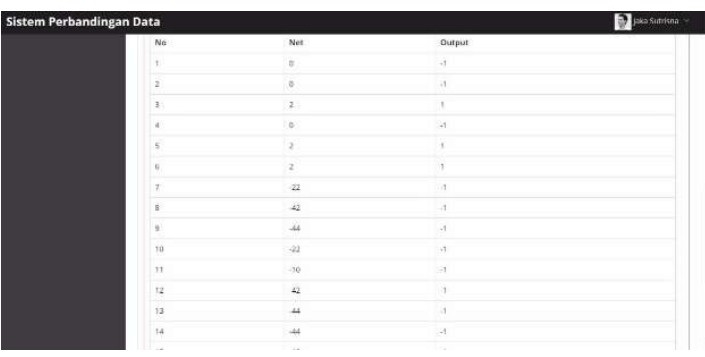

Gambar 4.5 output dari hanseng dan nikkei pada perhitungan algoritma hebbian.

\section{KESIMPULAN}

1) Dengan menggunakan metode jaringan saraf tiruan-algoritma hebbian maka dapat membandingkan antara nikkei dan hanseng mana yang lebih baik.

2) Metode Jaringan Syaraf Tiruan mempunyai sifat yang adaptif yaitu jaringan berusaha mencapai kestabilan kembali untuk mencapai output yang diharapkan. Hal ini disebabkan karena adanya proses belajar dengan penyesuaian bobot-bobot koneksi.

\section{SARAN}

Untuk lebih mengembangkan sistem ini, terbuka kesempatan untuk pengembangan penelitian yang lain dengan menggunakan metode yang sama atau metode baru yang lebih baik lagi. 


\section{DAFTAR PUSTAKA}

Felasufah Kusumadewi, "Peramalan Harga Emas FeedForword Neural Network Dengan Algoritma Backpropagation", Jurnal Matematika dan Ilmu Pengetahuan Alam, Universitas Negeri Yogyakarta, 2014.

Fachrul K.,dkk, "Peramalan Forex Syariah Menggunakan Saraf Tiruan Backpropagation", Jurnal Teknik Informatika, Sains dan Teknologi, Universitas Islam Negeri Maulana Malik Ibrahim Malang, Vol.4 15 Desember 2016.

Erico D.H., dan Lydia W.S., "Penerapan Jaringan Syaraf Tiruan Metode Propagasi Balik Dalam Pengenalan Tulisan Tangan Huruf Jepang", Jurnal Informatika, Teknik Informatika, Universitas Kristen Maranatha, Bandung, Vol.7 No.1 Juni 2011.

David, Sandi K., "Penerapan Algoritma Jaringan Saraf Tiruan Backpropagation Untuk Pengenalan Pola Tanda Tangan", Jurnal Teknologi,Sistem Informasi dan Teknik Informatika, STMIK Pontianak, Kalimantan Barat, Vol.6 No.2 Desember 2013.

Nuraeni Yeni, "Penerapan Jaringan Saraf Tiruan Untuk Mengukur Tingkat Korelasi Saraf Tiruan Untuk Mengukur Tingkat Korelasi Antara Nem Dengan Ipk Kelulusan Mahasiswa", Jurnal TELKOMNIKA, Teknik Informatika, Universitas Paramadina, Jakarta, Vol.7 No.3 Desember 2009.

Darmaji, dkk. Pasar Modal di Indonesia. Jakarta: Salemba Empat, 2006.

Hidayat, Taufik,Buku Pintar Investasi Syariah. Jakarta: Medikita, .2011.

Desiani, A. dan Arhami, M., Konsep Kecerdasan Buatan, Yogyakarta: Andi, 2006.

Noer Azam Achsani, Mencermati Kejatuhan Indeks Dow Jones: Akankah Indeks BEJ Ikut Terseret?.University Of Potsdam. Potsdam. 2000.

Ludovicus Sensi Wondabio, Analisa Hubungan Index Harga Saham Gabungan (IHSG) Jakarta (JSX), London (FTSE), Tokyo (Nikkei) dan Singapura (SSI). Simposium Nasional Akuntansi Padang. Padang, 2006. 